\title{
BIOLOGIA E CONTROLE MICROBIANO DE Urbanus acawoios (WILLIAMS， 1926) (LEPIDOPTERA: HESPERIIDAE): I. DESCRIÇÃO MORFOLÓGICA E ASPECTOS BIO-ECOLÓGICOS.
}

\author{
Manoel Dias NOGUEIRA ${ }^{1 \dagger}$, Mohamed E. M. HABIB ${ }^{2}$
}

\begin{abstract}
RESUMO - Devido aos danos dos ataques de Urbanus acawoios (Williams, 1926) (Lepidoptera: Hesperiidae) em palheteiras (Clitoria racemosa) (Leguminosae) em Manaus, AM e a total ausência de qualquer informação a respeito desta espécie, o presente trabalho foi desenvolvido visando a obtenção de conhecimentos que facilitem a identificação de métodos seguros e eficientes para o seu controle. Os estudos biológicos revelaram que este inseto é multivoltino, tendo duração média de 41,89 $\pm 0,98$ dias por geração. As condições climáticas na cidade de Manaus, a disponibilidade de alimentos, e possivelmente a ausência de inimigos naturais eficientes, parecem ser os fatores principais responsáveis pela ocorrência de erupções populacionais desta espécie. Enquanto o estágio larval consiste de 5 fases (ínstares) e dura em média 18,46 $\pm 1,28$ dias, o da pupa necessita $9,96 \pm 1,05$, e o adulto $13,47 \pm 0,27$ dias, sob condições de $30^{\circ} \mathrm{C}$ e $85 \%$ UR. Estudos morfológicos foram incluídos.
\end{abstract}

Palavras-chaves: Biologia, Surto populacional, Urbanus acawoios, Amazônia brasileira.

Biology and Microbial Control of Urbanus acawoios (Williams, 1926) (Lepidoptera: Hesperiidae): I. Bio-ecological Informations.

ABSTRACT - Due to the lack of informations concerning Urbanus acawoios (Williams, 1926) (Lepidoptera: Hesperiidae), and the severe damage caused by it in Clitoria racemosa trees in Manaus, AM, the present research was conducted, under semi-natural conditions, in order to obtain data about its biology and development. The occurrence of phytophagous pests in urban environments, in addition to causing troubles and problems, it needs special control methods, at least safety for the public health. Three consecutive generations were studied in the present work. As a multivoltine insect, the whole life cycle was observed to vary between 36 and 50 days, with an average of $41.89 \pm 0.98$ days. The oviposition behaviour, as well as the egg morphology were described. The embryonic development lasted between 3 and 4 days. External and internal alterations during the egg development were determined. The initial larval instars showed to be of aggregated habit, while the others were solitary. The larval stage, consisting of 5 instars, lasted an average of $18.46 \pm 1.28$ days, with a minimum of 19 and a maximum of 26 days. The biology of each instar and its duration time were also determined. The mid-gut $\mathrm{pH}$ of the larval stage varied between 8.4 and 9.2, with an average of 8,7 . The pupal stage lasted an average of $9.96 \pm 1.05$, with a minimum of 8 and a maximum of 12 days for its development. The mated adult longevity varied between 9 and 22 days, with an average of $13.47 \pm 0.27$ days.

Key-words: Biology, Outbreaks, Urbanos acawoios.

\section{INTRODUÇÃO}

Urbanus acawoios (Williams, 1926) (Lepidoptera: Hesperiidae) é conhecido como praga de palheteira,
Clitoria racemosa (Leguminosae). Esta leguminosa é uma planta ornamental e de sombra, amplamente distribuída na cidade de Manaus, AM. É comum nos campi do Instituto

(1+) "In memoriam" - Instituto Nacional de Pesquisas da Amazônia - INPA, Manaus - AM.

(2) IB - Zoologia -Universidade Estadual de Campinas - UNICAMP - Campinas - SP. O segundo autor deste trabalho deixa registrado, aqui, a saudade que os entomólogos e demais pesquisadores do INPA sentem pelo falecimento precoce do primeiro autor, o jovem Manoel Dias Nogueira. 
Nacional de Pesquisas da Amazônia (INPA) e da Universidade do Amazonas (UA), na arborização das ruas e avenidas da cidade, no pátio do Aeroporto Internacional Eduardo Gomes e, inclusive, em jardins de residências. Ainda, é usada para sombreamento de cacau e café na região, e contribui para a nitrogenização do solo através dos nódulos bacterianos nas suas raízes.

Ocorrem em Manaus, esporadicamente, violentos surtos populacionais deste hesperídeo, durante duas ou três gerações, causando sérios problemas e distúrbios que variam de acordo com o local atingido. A quantidade, muito grande, de lagartas por árvore, e o deslocamento das larvas maduras em busca de sítios para se transformarem em crisálidas, invadindo laboratórios, bibliotecas, escritórios e residências são alguns aspectos de impacto direto. O desfolhamento total das árvores e a grande quantidade de adultos no ambiente, também devem ser levados em consideração.

A família Hesperiidae é composta por três sub-famílias: Phyrrhopyginae, Hesperiinae e Pyrginae. A última destaca-se por ter espécies de importância econômica (Hayward, 1932; Monte, 1934; Costa Lima, 1949; Margheritis \& Rizzo, 1965) como U. acawoios e $U$. proteus. Enquanto a última recebe alguma atenção na pesquisa entomológica brasileira (Monte, 1934; D'Almeida, 1944; Freitas, 1960; Dam \& Wilde, 1977), U. acawoios é praticamente desconhecida e muitas vezes foi incorretamente identificada.

O presente trabalho tem como objetivo estudar a biologia de $U$. acawoios sob condições laboratoriais e de campo, visando conhecer melhor este hesperídeo fitófago. Tal estudo é fundamental para estabelecer estratégias de controle desta praga, coerentes e compatíveis com o ambiente urbano onde ela ocorre.

\section{MATERIAL E MÉTODOS}

Durante o período de um surto populacional de $U$. acawoios (julho a dezembro de 1984), na cidade de Manaus - AM, foram coletadas algumas centenas dos seus diferentes estágios evolutivos, ovos, larvas, pupas e adultos, a partir de visitas diárias às palheteiras do pátio do INPA e do campus da UA. Os procedimentos usados nas investigações biológicas foram adaptados de Habib (1977; 1978) e Patel \& Habib (1978).

Os ovos coletados no campo, eram transferidas para o Laboratório de Entomologia do Curso de PósGraduação do INPA, inventariados, contando o número de ovos depositados em cada ponteiro e colocados em placas de Petri $(10 \mathrm{~cm}$ de diâmetro). As larvas eclodidas eram mantidas agregadas, nas mesmas placas, até o início do $3^{\circ}$ ínstar, quando então eram separadas em grupos de 10 e mantidas até o estágio de pupa em vidros de $20 \mathrm{~cm}$ de altura por $10 \mathrm{~cm}$ de diâmetro, cobertos por filó. Diariamente, os recipientes eram limpos e o alimento renovado por folhas novas e tenras. Foram sacrificadas 30 larvas de cada ínstar 
para medição do comprimento e largura das cápsulas cefálicas, e conseqüentemente os índices de crescimento larval.

Após a emergência, os adultos foram transferidos para gaiolas de tela de nailon $(35 \times 35 \times 40 \mathrm{~cm})$, onde uma solução de sacarose a $10 \%$ era desponibilizada em pedaços de algodão. No interior da gaiola eram mantidos galhos de $C$. racemosa como sítio de oviposição. A temperatura e a umidade relativa do ar eram registradas, e as médias diárias foram calculadas a partir de três leituras por dia, a cada oito horas.

\section{RESULTADOS E DISCUSSÃO}

Os estudos foram realizados sob condições normais de laboratório, onde a temperatura oscilou entre $27^{\circ}$ e $33^{\circ} \mathrm{C}$, com uma média de $30,35^{\circ} \mathrm{C}$; e a umidade relativa variou de 75 a $91 \%$, sendo a média de $85 \%$.

As fêmeas fecundadas de $U$. acawoios depositam os seus ovos, em grupos, nos ponteiros (lançamento de folhas novas) de sua planta hospedeira, Clitoria racemosa, no lado inferior como no superior das folhas, bem como nos pecíolos (Fig. 1). De formato oval, os ovos medem $0,64 \mathrm{~mm}$ $\pm 0,002$ de largura e $0,76 \mathrm{~mm} \pm 0,002$ de comprimento. A topografia do córion apresenta 11 ou 12 indentações na superfície externa.

Logo após a oviposição, os ovos apresentam uma cor amarela creme; em pleno desenvolvimento embrionário, tornam-se vermelho alaranjados e imediatamente antes da eclosão mudam para branco transparente. Nesta última fase, podese visualizar facilmente a cor preta da cabeça da larva ainda dentro do córion. As posturas observadas no campo revelaram 23 a 307 ovos por ponteiro (média de 103,89 ovos).

O período de incubação (desenvolvimento embrionário), sob as condições experimentais, variou de 3 a 4 dias, e a viabilidade foi em média de $99,09 \%$. Não se detectou a ocorrência de parasitismo nesta fase.

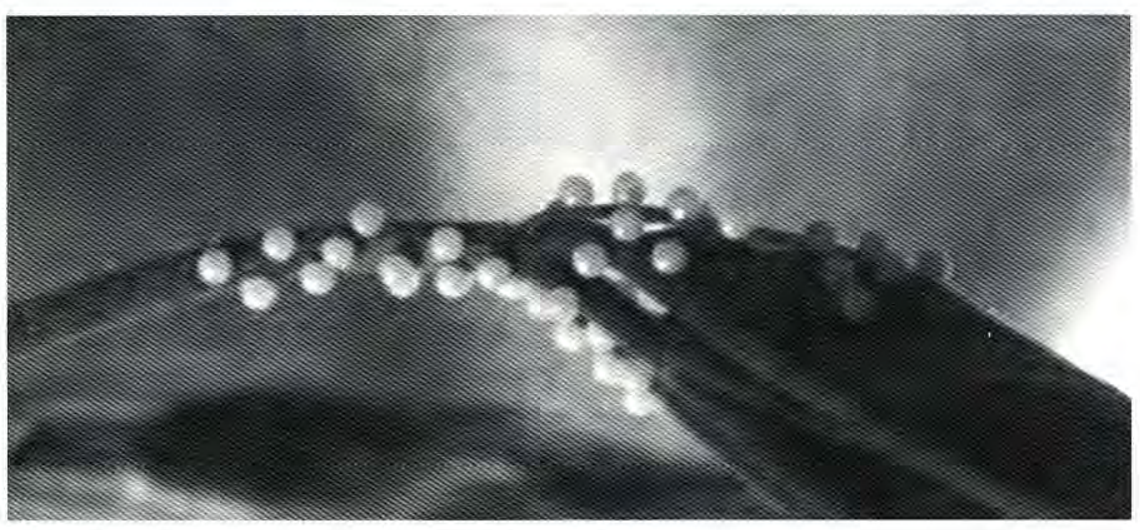

Figura 1. Ovos de Urbanus acawoios recém depositados em pecíolos de palheteiras. 
De acordo com Dam et al. (1977), o desenvolvimento embrionário dos ovos de $U$. proteus, durou em média 4,3 dias, sob temperatura que variou de 13 a $22^{\circ} \mathrm{C}$.

O estágio larval de compreende cinco ínstares separados por quatro ecdises. Durante as primeiras três fases larvais, as lagartas vivem agrupadas (Figs 2, 3) e são de coloração amarelada, com a cápsula cefálica de coloração preta brilhante. Nos últimos dois instares, apresentam coloração amarelada, linha preta longitudinal mediana dorsal, duas linhas pretas mais largas longitudinais laterais e manchas longitudinais dorsolateralmente ao longo do corpo. A cápsula cefálica, quase na sua totalidade, apresenta duas manchas laterais de cor marrom clara (Fig. 4). Cada larva constrói seu próprio abrigo, enrolando uma parte da folha, ligandoa com fios de seda, e nele vive até o final do $5^{\circ}$ ínstar quando, então, abandona a planta hospedeira a procura de um lugar para transformarse em crisálida.

As lagartas alimentam-se, inicialmente, dos bordos das folhas, consumindo em seguida o restante do limbo, permanecendo apenas as nervuras. Durante o surto populacional observado no presente trabalho, houve desfolhamento quase total da maioria das árvores das palheteiras monitoradas. Após cada ecdise, as lagartas alimentam-se das exúvias, deixando apenas as cápsulas cefálicas. Embora a determinação do

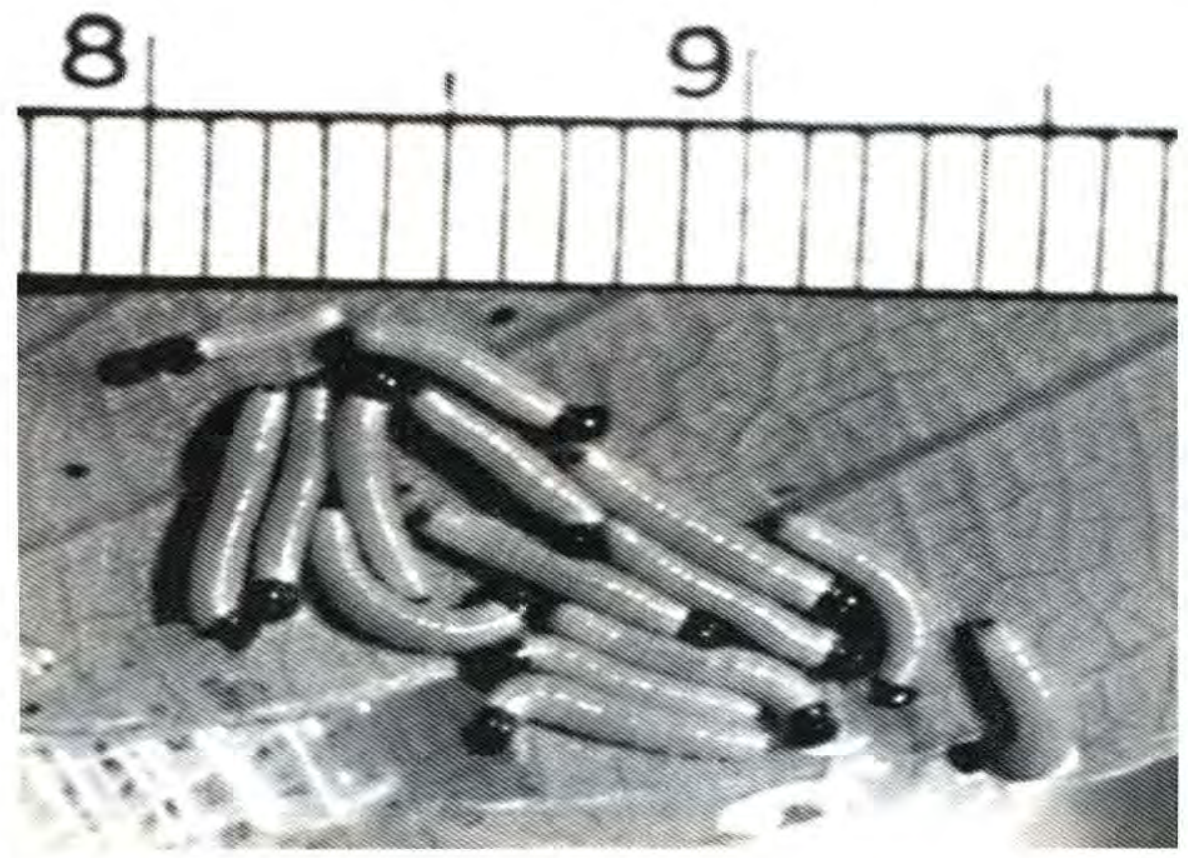

Figura 2. Larvas de segundo ínstar de Urbanus acawoios. 


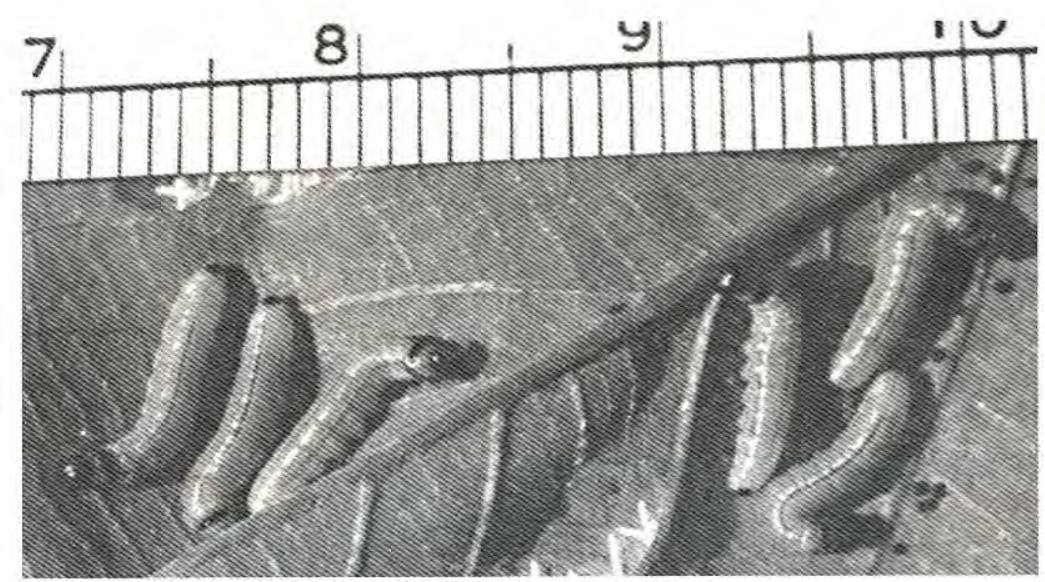

Figura 3. Larvas de terceiro ínstar de Urbanus acawoios.

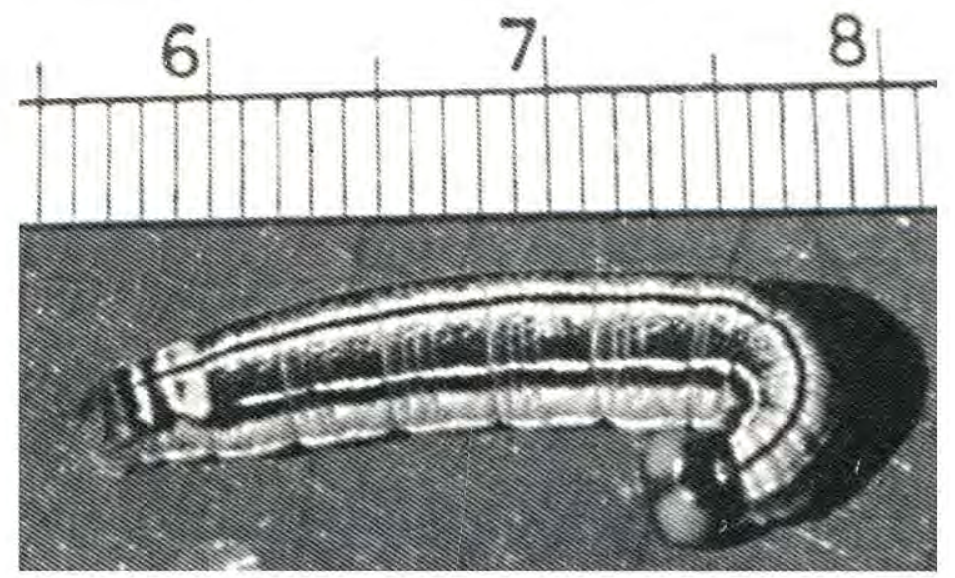

Figura 4. Larvas de quinto ínstar de Urbanus acawoios.

número de ínstares larvais tenha sido baseada na presença das cápsulas cefálicas deixadas após cada ecdise, estas não foram utilizadas para as medidas de largura e comprimento, pois a maioria se rompe durante o processo, podendo prejudicar os cálculos dos Índices de Crescimento (detalhes nas Tabs 1 e 2).

O tempo médio de duração de cada ínstar de $U$. acawoios foi de 1,00 $\pm 0,0 ; 2,41 \pm 0,24 ; 3,05 \pm 0,11 ; 4,97$ $\pm 0,11$ e de $10,20 \pm 0,11$ dias, respectivamente. A mortalidade natural do estágio larval foi extremamente reduzida $(4,53 \%)$, indicando que as condições climáticas eram bastante favoráveis ao desenvolvimento deste hesperídeo, e possivelmente sejam a causa direta da erupção populacional observada. Dam \& Wilde (1977), também, encontraram cinco fases larvais para $U$. proteus e com tempos 
Tabela 1. Largura da cápsula cefálica $(\mathrm{mm})$ dos diferentes ínstares e Índices de Crescimento de Urbanus acawoios.

\begin{tabular}{lccccc}
\hline \multicolumn{5}{c}{ LARGURA DA CÁPSULA CEFÁlICA } \\
\hline \multirow{7}{*}{$\begin{array}{l}1^{\circ} \text { instar } \\
\text { Média }\end{array}$} & $2^{\circ}$ instar & $3^{\circ}$ instar & $4^{\circ}$ instar & $5^{\circ}$ ínstar \\
Máxima & $0,41 \pm 0,03$ & $0,65 \pm 0,01$ & $1,18 \pm 0,24$ & $2,01 \pm 0,02$ & $2,97 \pm 0,55$ \\
Minima & 0,30 & 0,70 & 1,30 & 2,20 & 3,20 \\
Índice Cres. & 0,60 & 1,00 & 1,80 & 2,80 \\
Índice médio de crescimento larval $=1,47$ & 1,80 & 1,71 & 1,48 \\
\hline
\end{tabular}

Tabela 2. Comprimento da cápsula cefálica $(\mathrm{mm})$ dos diferentes ínstares e Índices de Crescimento de Urbanus acawoios.

\begin{tabular}{lccccc}
\hline \multicolumn{5}{c}{ COMPRIMENTO DA CÁPSULA CEFÁLICA } \\
\hline \multirow{2}{*}{$1^{\circ}$ instar } & $2^{\circ}$ instar & $3^{\circ}$ instar & $4^{\circ}$ ínstar & $5^{\circ}$ instar \\
Média & $0,45 \pm 0,05$ & $0,75 \pm 0,32$ & $1,34 \pm 0,01$ & $2,22 \pm 0,25$ & $3,36 \pm 0,01$ \\
Mínima & 0,60 & 0,90 & 1,50 & 2,40 & 3,20 \\
Índice Cres. & 0,40 & 0,60 & 1,20 & 2,00 & 2,80 \\
Índice médio de crescimento larval $=1,66$ & 1,687 & 1,661 & 1,511 \\
\hline
\end{tabular}

de duração $(2,8 ; 2,9 ; 3,2 ; 4,7$ e 9,2 dias, respectivamente) próximos aos valores registrados no presente trabalho.

Enquanto o estágio larval de $U$. acawoios apresentou uma duração média, no presente trabalho, calculada em 18,46 $\pm 1,28$ dias, Costa Lima (1949) observou um intervalo de 18 a 20 dias e Dam \& Wilde (1977) calcularam uma média de 22,8 dias para o mesmo estágio de $U$. proteus.

No campo, foram observadas e coletadas larvas parasitoidadas por taquinídeos e várias outras por Apanteles sp. (Hymenoptera). Costa Lima (1949) e Jimenez (1973) encontraram dípteros taquinídeos como Lespesia sp. e Blondelia sp e himenópteros parasitoidando larvas de U. proteus. Dam \& Wilde (1977) encontraram indivíduos, deste mesmo hesperídeo, parasitados por Ardalus sp. (Hymenoptera) e Calpodomyia sp. (Diptera).

Quando a lagarta atinge o fim do $5^{0}$ ínstar, abandona o seu abrigo na folha e desce da planta, procurando um lugar para se transformar em crisálida. Normalmente, procura local fresco e escuro, como cantos, buracos e frestas, onde a lagarta se fixa com a parte terminal do abdome, retomando o processo de metamorfose e transformação em pré-pupa, de coloração preta e tamanho reduzido. Após no máximo um dia nesta fase, ocorre a transformação em crisálida 
fixa no substrato pelo cremáster. Inicialmente, a crisálida é de coloração verde amarela, adquirindo a cor marrom poucas horas depois (Fig. 5).

Não houve nenhum registro, durante $o$ presente trabalho, de transformação em crisálida nas dobras das folhas da planta hospedeira, o que é comum com $U$. proteus (D'Almeida, 1944; Costa Lima, 1949; Dam \& Wilde, 1977). No laboratório, por outro lado, e devido à limitação de espaço, algumas crisálidas foram formadas no chão da gaiola, entre dobras de folhas, envolvidas sempre por fios de seda produzidos pela larva.

A duração da fase de crisálida (Tab. 3), apresentou em média 9,96 \pm 1,05 dias (máximo de 12 e mínimo de
8 dias). Apenas de $8,37 \%$ das crisálidas não alcançaram o estágio adulto, e o parasitoidismo por taquinídeos foi observado. Dados biológicos, em ambientes mais amenos, revelaram tempos de duração de crisálidas de $U$. proteus de 16 dias (D'Almeida, 1944), 12 (Costa Lima, 1949), 14 a 15 (Freitas, 1960) e 11,4 dias (Dam \& Wilde, 1977), mais prolongados que o obtido no presente trabalho para $U$. acawoios.

Os adultos de $U$. acawoios (Fig. 6), tiveram uma longevidade média de $13,47 \pm 0,27$ dias (máximo de $22 \mathrm{e}$ mínimo de 9 dias) (Tab. 3), próxima da observada para U. proteus (Dam et al., 1977). Sob condições de laboratório, não foi possível observar

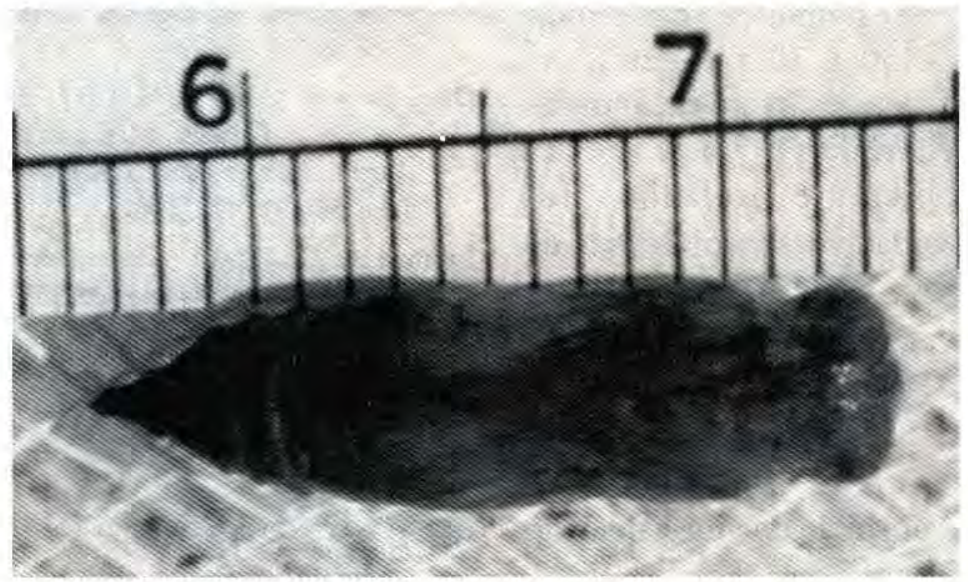

Figura 5. Estágio de crisálida de Urbanus acawoios.

Tabela 3. Duração, em dias, das diferentes fases e taxa de mortalidade natural dos estágios, larval e pupal de Urbanus acawoios.

\begin{tabular}{lcccc}
\hline \multicolumn{1}{c}{ Estágio } & $\mathrm{n}$ & Duração (média $\pm \mathrm{dp}$ ) & Intervalo & Mortalidade Natural \\
\hline Larval & 200 & $18,46 \pm 1,28$ & $26-19$ & $4,50 \%$ \\
Crisálida & 191 & $9,96 \pm 1,05$ & $12-8$ & $8,37 \%$ \\
Adulto & 175 & $13,47 \pm 0,27$ & $22-9$ & \\
Ciclo Total & 175 & $41,89 \pm 0,89$ & $50-36$ & \\
\hline
\end{tabular}




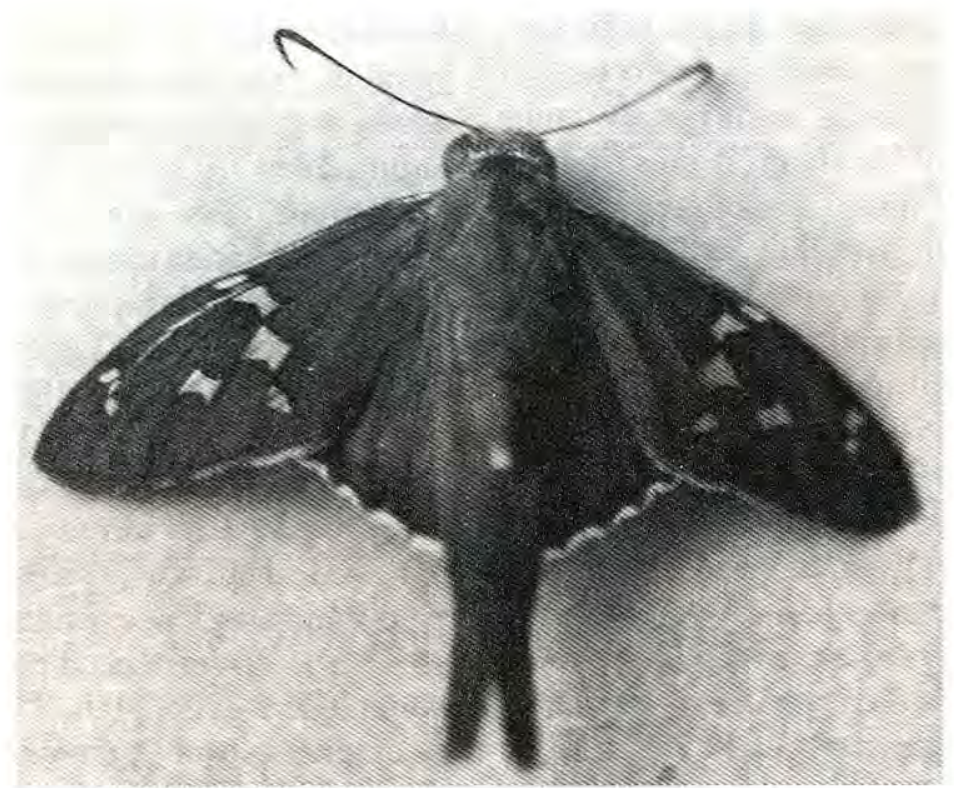

Figura 6. Adulto de Urbanus acawoios.

acasalamento e oviposição nas gaiolas de criação $(50 \times 70 \times 80 \mathrm{~cm})$. As memas dificuldades foram encontradas por Dam \& Wilde, (1977).

No presente trabalho, foi possível estudar o desenvolvimento de $U$. acawoios, durante três gerações consecutivas, obtendo-se uma média por ciclo de 41,89 $\pm 0,89$ dias, com o máximo de 50 e o mínimo de 36 dias. Urbanus proteus, por outro lado, apresentou um ciclo de vida calculado em média de 49,5 dias (Dam \& Wilde, 1977), pouco superior à de $U$. acawoios.

\section{Bibliografia Citada}

Costa Lima, A. M. 1949. Insetos do Brasil -

6 Tomo - Lepidopteros - 2" parte. Escola Nacional de Agronomia, RJ., Série Didática no. 8.

D'Almeida, R. F. 1944. Estudos biológicos sobre alguns lepidópteros do Brasil. Arq. Zool., SP. 4 : 33-70.

Dam, W. van \& Wilde, G. 1977. Biology of Bean Leaf-roller, Urbanus proteus (Lepid., Hesperiidae). J. Kansas Entomol. Soc., 50(19): 157-160.

Freitas, A. O. 1960. "Cabeça de fósforo". Nova praga do feijoeiro em Pernambuco. Arq. Inst. Pesq. Agr., 5: 345-363.

Habib, M. E. M. 1977. Contribution to the biology of the American cotton leafworm, Alabama argillacea (Hübner) (Lepid., Noctuidae). Z. ang. Ent., 84: 412-418.

Habib, M. E. M. 1978. Effect of várious larval and adult diets on the American cotton leafworm, Alabama argillacea (Hübner) (Lepid., Noctuidae). Z. ang. Ent., 85: 219-224.

Hayward, K. J. 1932. Lepidópteros argentinos. Família Hesperiidae. Rev. Soc. Entomol. Arg., 5(21): 19-35.

Jimenez, R. F. 1973. Dipteros parasitos de larvas de lepidopteros en algunos municipios de Valle del Cauca. Acta Agron., Colombia, 23(1-2): 7-50. 
Margheritis, A. E.; Rizzo, H. F. E. 1965. Lepidopteros de InteresseAgrícola. Editorial Sudamericana, Buenos Aires, 1997 pp.

Monte, O. 1934. Borboletas que vivem em plantas cultivadas. Sec. De-Agric., MG, Série Agrícola no. 21, 220 pp.

Patel, P. N.; Habib, M. E. M. 1978. Biologi$\mathrm{cal}$ and behavioral studies of an ovoviviparous earwig, Marava arachidis (Yersin, 1860) (Dermaptera, Forficulidae). Rev. Biol. Trop., 26(2): 385-389. 